\title{
Characterization of Multiple Exon 1 Variants in Mammalian HuD mRNA and Neuron-Specific Transcriptional Control via Neurogenin 2
}

\author{
Lucas M. Bronicki, Guy Bélanger, and Bernard J. Jasmin \\ Department of Cellular and Molecular Medicine, Faculty of Medicine, University of Ottawa, Ottawa, Ontario K1H 8M5, Canada
}

\begin{abstract}
The RBP (RNA-binding protein) and Hu/ELAV family member HuD regulates mRNA metabolism of genes directly or indirectly involved in neuronal differentiation, learning and memory, and several neurological diseases. Given the important functions of HuD in a variety of processes, we set out to determine the mechanisms that promote HuD mRNA expression in neurons using a mouse model. Through several complementary approaches, we determined that the abundance of HuD mRNA is predominantly under transcriptional control in developing neurons. Bioinformatic and 5'RACE (rapid amplification of cDNA ends) analyses of the $5^{\prime}$ genomic flanking region identified eight conserved HuD leader exons (E1s), two of which are novel. Expression of all E1 variants was determined in mouse embryonic (E14.5) and adult brains. Sequential deletion of the $5^{\prime}$ regulatory region upstream of the predominantly expressed E1c variant revealed a well conserved $400 \mathrm{bp}$ DNA region that contains five E-boxes and is capable of directing HuD expression specifically in neurons. Using EMSA (electrophoretic mobility shift assay), ChIP (chromatin immunoprecipitation), and $5^{\prime}$ regulatory region deletion and mutation analysis, we found that two of these E-boxes are targets of Neurogenin 2 (Ngn2) and that this mechanism is important for HuD mRNA induction. Together, our findings reveal that transcriptional regulation of $\mathrm{HuD}$ involves the use of alternate leader exons and Ngn2 mediates neuron-specific mRNA expression. To our knowledge, this is the first study to identify molecular events that positively regulate HuD mRNA expression.
\end{abstract}

\section{Introduction}

The predominantly neuron-restricted HuD/Elavl4 is a member of the Hu/ELAV-like family of RNA-binding proteins (RBPs) that also includes $\mathrm{HuR}, \mathrm{HuB}$, and $\mathrm{HuC}$ (for review, see Hinman and Lou, 2008; Pascale et al., 2008). HuD is one of the earliest markers of neuronal differentiation, being expressed by $10 \mathrm{~d}$ of brain development (Hambardzumyan et al., 2009). Moreover, localization of $\mathrm{HuD}$ in the adult mouse brain is also slightly distinct from other Hu members with abundant expression detected in regions such as the olfactory bulb, retina, and cortex (Okano and Darnell, 1997; Clayton et al., 1998). The developmental and localized expression of $\mathrm{HuD}$ in the brain is reflective of its established roles in neuronal differentiation and function (for review, see Deschênes-Furry et al., 2006). In addition, HuD has also been implicated in neuronal regeneration following axotomy (Anderson

\footnotetext{
Received May 9, 2012; revised June 15, 2012; accepted June 22, 2012

Author contributions: L.M.B. and B.J.J. designed research; L.M.B. and G.B. performed research; L.M.B., G.B., and B.J.J. analyzed data; L.M.B. and B.J.J. wrote the paper.

This work was supported by a Canadian Institutes of Health Research grant to B.J.J. We thank Matthew Andrusiak and Dr. Vladimir Ruzhynsky from Dr. Ruth Slack's laboratory (University of Ottawa, Canada) for helping with mouse embryonic brain extraction and Drs. Ilona Skerjanc (University of Ottawa, Canada), Carol Schuurmans (University of Calgary, Canada), Valerie Wallace (Ottawa Hospital Research Institute, Ottawa, Canada), Marc Ekker (University of Ottawa, Canada), Gabriel Sanchez and Jocelyn Côté (University of Ottawa, Canada) for providing reagents. We also thank all members of the Jasmin laboratory for technical assistance and insightful discussions.

The authors declare no competing financial interests.

Correspondence should be addressed to Bernard J. Jasmin, 451 Smyth Road, 0ttawa, ON K1H 8M5, Canada. E-mail:jasmin@uottawa.ca.

DOI:10.1523/JNEUROSCI.2247-12.2012

Copyright $\odot 2012$ the authors $\quad 0270-6474 / 12 / 3211164-12 \$ 15.00 / 0$
}

et al., 2003; Deschênes-Furry et al., 2007) or seizure (Bolognani et al., 2007; Tiruchinapalli et al., 2008), learning and memory (Quattrone et al., 2001), and numerous pathologies, including Alzheimer's and Parkinson's disease (Noureddine et al., 2005; Amadio et al., 2009), and spinal muscular atrophy (Hubers et al., 2011). At the intracellular level, HuD typically binds to U-rich elements in the 3' untranslated region (UTR) and poly(A) tails to regulate transcript stability, transport, and translation. In addition, HuD binds to other ciselements within target transcripts, thereby regulating splicing and alternate polyadenylation (for review, see Pascale and Govoni, 2012). Numerous $\mathrm{HuD}$ target transcripts have been identified over the years and many encode proteins that are involved in processes ranging from neuronal progenitor cell proliferation (i.e., Msi-1) to neuritogenesis (i.e., GAP-43 and AChE) (Bolognani et al., 2010). Despite the multifunctional roles of $\mathrm{HuD}$, relatively little is known regarding the molecular mechanisms that govern its expression in neurons.

Only a few studies have so far examined transcriptional and/or post-transcriptional mechanisms controlling mammalian expression of HuD. For instance, the Thyroid hormone (T3) and the transcription factor FoxO1 have been shown to decrease transcription of $\mathrm{HuD}$ in cultured neuronal (Cuadrado et al., 2003) and pancreatic $\beta$ (Lee et al., 2012) cells, respectively. Moreover, all ELAV members are known to interact with the HuD 3'UTR in vivo, implying autoregulation by $\mathrm{HuD}$ (Bolognani et al., 2010). The consequences of these interactions are unknown but could involve altered mRNA processing, stability, or translation (Abe et al., 1996; Samson, 1998; Mansfield and Keene, 2012). Last, a 
Table 1. Primer sequences

\begin{tabular}{|c|c|c|}
\hline Name & Forward & Reverse \\
\hline $\mathrm{HuD}$ & CAATACGGTCGCATCATCAC & CCTTTGATGGCTTCTTCTGC \\
\hline Gap-43 & GCTCAGCGGAGACAGAAAGTG & CACATCGGCTTGTTTAGGCTC \\
\hline $18 \mathrm{~S}$ & CGCCGCTAGAGGTGAAATC & CCAGTCGGCATCGTTTATGG \\
\hline Brachyury T & CTGGACTTCGTGACGGCTG & TGACTTTGCTGAAAGACACAGG \\
\hline $\operatorname{Ngn} 2$ & AAGGCACAGCCAGAAGAAAA & CGTCTTCTGACCAAACAGCA \\
\hline E1a & GGACCCAGTGAGAAGCGACT & GTTCTGGAGCCTCATCTTCG \\
\hline $\mathrm{Ela}^{1}$ & AGAACAGGAGGCAAGGTCTG & ATTAGGGCAGTTCCAGAGCA \\
\hline $\mathrm{E}_{1} \mathrm{a}^{2}$ & TGAAATCAGCAGGACGCTTA & CCTGAATTCCTCTTGGGTCA \\
\hline $\mathrm{E}_{1} \mathrm{a}^{3}$ & GGCTGCCTGATATGGGATTA & CATAAATGAGCAGTTTCTTGACTC \\
\hline $\mathrm{E} 1 \mathrm{a}^{4}$ & GACCTGCAGTTGTGACAGGA & CCTTTTACCTTCTTCCAGCTCA \\
\hline E1b & ССACCCCCTCCCAATAATAG & CAGCGCTTCGACTCTTCTCT \\
\hline E1c & GAACGTTGAGATGGGCAGTT & ATACAAGCCGCCTCCTCTTT \\
\hline $\mathrm{E} 1 c^{1}$ & ACGCTCCTTTCTGCTTTTGA & GCATTTGGCATGATCTTTTG \\
\hline E2 & - & TGACCCAAGAGGAATTCAGG \\
\hline pLUC3.4 & GGCTGCCTGATATGGGATTA & CCATTCCACTCCATCTGTGA \\
\hline pLUC1.0 & GCTAGCCGACCTGCAGTTGTGACAGG & AGATCTCCAAGCCATTCCACTCCATC \\
\hline pLUC0.6 & ССАССССТТCCСATAATAG & ССАTTCСАСТССАTCTGTGA \\
\hline pLUC1.0Me2 & CCAATCAGAGTCTGGCTTCTGCACACAGATGGTCCCATAAATG & CATTTATGGGACCATCTGTGTGCAGAAGCCAGACTCTGATTGG \\
\hline pLUC1.0Me3 & AGAGTCTGGCTTCAGCTGACTGAACGTCCCATAAATGGATGTAAA & TTTACATCCATTTATGGGACGTTCAGTCAGCTGAAGCCAGACTCT \\
\hline pLUC1.0Me2 +3 & CCCAGCCAATCAGAGTCTGGCTTCTGCACACTGAACGTCCCATAAATGGATGTAAAAAGG & CCTTTTTACATCCATTTATGGGACGTTCAGTGTGCAGAAGCCAGACTCTGATTGGCTGGG \\
\hline ChIP_E2 + 3 & GCCGGGCTTTAATTACCAGA & TGAACAGAGCCTTGCTGAAA \\
\hline ChIP_ $\beta$ RARE & CTGCTGGGAGTTTTTAAGC & GGCAAAGAATAGACCCTCC \\
\hline
\end{tabular}

Forward and reverse primer sequences used in semiquantitative and quantitative real-time RT-PCR. The annealing temperature for each primer set was $60^{\circ} \mathrm{C}$.

recent study has also found that miR-375 decreases abundance of $\mathrm{HuD}$ by altering both its mRNA stability and translation (Abdelmohsen et al., 2010). Interestingly, these studies indicate that currently only factors that negatively regulate expression of $\mathrm{HuD}$ are known, further stressing the importance of delineating the molecular mechanisms controlling spatial and temporal induction of $\mathrm{HuD}$.

Here, we set out to characterize the $5^{\prime}$ genomic region of the $H u D$ gene and identify molecular events that positively control its mRNA in differentiating neurons. Our findings demonstrate that the mammalian $H u D$ gene contains eight leader exons and highlight the key role of Neurogenin 2 (Ngn2) in mediating expression of HuD mRNA through a neuron-specific transcriptional mechanism.

\section{Materials and Methods}

Cell culture and animals. The P19 cell line was kindly provided by Dr. Ilona Skerjanc (University of Ottawa, Ottawa, ON, Canada). Cells were cultured in growth media consisting of $\alpha$ modified eagle medium $(\alpha \mathrm{MEM})$, supplemented with $1 \mathrm{~mm} \mathrm{~L}$-glutamine, penicillin $(20 \mathrm{U} / \mathrm{ml})$, streptomycin $(20 \mathrm{mg} / \mathrm{ml}), 2.5 \%$ fetal bovine serum, and $7.5 \%$ fetal calf serum (ATCC). Cells were incubated at $37^{\circ} \mathrm{C}$ in a saturated humidity atmosphere containing $95 \%$ air and $5 \% \mathrm{CO}_{2}$. To induce P19 differentiation into neuronal or mesodermal lineages, cells were resuspended in growth media containing $0.5 \mu \mathrm{M}$ all-trans retinoic acid (RA; SigmaAldrich) or $0.08 \%(\mathrm{v} / \mathrm{v})$ dimethyl sulfoxide (DMSO; Sigma-Aldrich), respectively, in ultra-low attachment six-well plates (Corning). All media were changed every $2 \mathrm{~d}$.

Brain tissues were extracted from adult (10-12 weeks) and embryonic (E14.5) C57BL/6 (Jackson Laboratories) male and female mice. For the embryonic time point, days were counted from the first appearance of a vaginal plug. Animals were housed two per cage, on a regular $12 \mathrm{~h}$ day/ night cycle and had ad libitum access to both standard food chow and water. The University of Ottawa Animal Care and Use Committee (ACUC) and Animal Care and Veterinary Service (ACVS) approved all procedures.

RNA extraction, semiquantitative $R T-P C R$, and real-time quantitative PCR. Total RNA was isolated from P19 cells and mouse brain with TRIzol as recommended by the manufacturer (Invitrogen) and as previously described (Boudreau-Larivière et al., 2000). RNA was subjected to DNase treatment (Promega) and subsequently stored at $-80^{\circ} \mathrm{C}$ until use. RNA samples were quantified using the Gene Quant II spectrophotometer (GE Healthcare). Reverse transcription (RT) reactions were performed as previously described (Clow and Jasmin, 2010).

Semiquantitative PCR and quantification was performed as previously described (Deschênes-Furry et al., 2007). Annealing temperature and PCR cycle numbers within linear range of amplification were first determined for each primer set (Table 1). Real-time quantitative PCR was performed as previously described (Clow and Jasmin, 2010). Annealing temperatures for all primer sets were $60^{\circ} \mathrm{C}$.

$5^{\prime}$ Rapid amplification of cDNA ends assay. 5' Rapid amplification of cDNA ends (RACE) was performed using the FirstChoice RLM-RACE kit (Ambion) according to the manufacturer's protocol. RNA (100 ng) from 4 d RA-differentiated P19 cells with a specific inner reverse E2 primer (Table 1) was used for the assay. PCR products were resolved on a $1.5 \%$ agarose gel, purified using a Gel Extraction Kit (Qiagen), cloned into pCR2.1-TOPO plasmids (Invitrogen), and sequenced. All novel sequences are available on GenBank (accession numbers; DQ460221, JX178292, and DQ437511).

Actinomycin D experiments and mRNA half-life calculations. Actinomycin D experiments were performed as previously described (Gramolini and Jasmin, 1999). For these, 4 d differentiated (with RA or DMSO) P19 cells were treated with $4 \mu \mathrm{g} / \mu \mathrm{l}$ Actinomycin D (Sigma-Aldrich). Total RNA from cell lysates was harvested at different time points $(0,2,4$, and $8 \mathrm{~h}$ ) post-treatment using TRIzol and processed for GPCR analysis (see above). The average ratios of RA-treated versus DMSO-treated samples from four independent experiments (with their SEs) were converted to natural logarithms ( $y$-axis) and then plotted against time ( $x$-axis). Exponential regression trend lines were then fit to the plotted data using Microsoft Excel software. The half-life was calculated as $t_{1 / 2}=(\ln (50 /$ $\mathrm{N}) / \lambda$ ) where $\lambda$ is the decay constant.

Nuclear run-on assays. Nuclear run-on assays were performed as previously described (Rolfe and Sewell, 1997). Briefly, nuclear extracts were harvested from neuron or mesoderm differentiated P19 cells using the ProteoJet Nuclear and Cytoplasmic Protein Extraction kit (Fermentas), according to manufacturer's protocol. Nuclei were split into two aliquots and incubated in a transcription reaction mix containing $20 \%$ glycerol, $30 \mathrm{~mm}$ Tris- $\mathrm{HCl} \mathrm{pH} \mathrm{8.0,} 2.5 \mathrm{~mm} \mathrm{MgCl}_{2}, 150 \mathrm{~mm} \mathrm{KCl}, 1$ mM DTT, $40 \mathrm{U}$ of Rnasin and 0.5 mM rATP, rCTP, rGTP, and rUTP $(+)$ or diethylpyrocarbonate (DEPC)-treated water (-) (Promega). Reactions were incubated for $30 \mathrm{~min}$ at $30^{\circ} \mathrm{C}$, then RNA was TRIzol extracted and real-time 
qPCR was performed with $\mathrm{HuD}$ and $18 \mathrm{~S}$ primers. Expression levels were quantified using the $\Delta \Delta \mathrm{C}_{\mathrm{t}}$ method and values were normalized to $18 \mathrm{~S}$ rRNA.

Promoter-reporter plasmids, mutagenesis, and Luciferase assays. The PC1G2-Ngn2, pCDNA3-NeuroD, pCDNA3-Mash1, and pCDNA3-E47 constructs were kindly provided by Drs. Carol Schuurmans (University of Calgary, Calgary, AB, Canada), Valerie Wallace (Ottawa Hospital Research Institute, Ottawa, ON, Canada), and Marc Ekker (University of Ottawa, Ottawa, ON, Canada), respectively. The bacterial artificial clone (BAC clone RP23-283L16.1; Pubmed AL627425.15), encompassing the mouse $\mathrm{HuD}$ gene locus, was kindly provided by The Wellcome Trust Sanger Institute (BioScience LifeSciences). All HuD promoter fragments were PCR amplified or restriction enzyme digested, resolved on a $1.5 \%$ agarose gel, gel extracted (Qiagen), and ligated into the MCS of the PGL4.14 vector (Stratagene). To create pLUC3.4, E1a ${ }^{3}$ forward and E1c reverse primers (Table 1 ) were used to PCR amplify a $3.820 \mathrm{~Kb}$ fragment, from the RP23 clone, which was then subcloned into a TA TOPO4.0 vector. This construct was digested with Not1, blunted with Klenow fragments (Fermentas), and then digested with Spe1. The resulting $3.742 \mathrm{~Kb}$ fragment was inserted between the Nhe1 and EcoRV sites in the PGL4.14 vector. The pLUC2.5 construct was produced by cutting out an $\sim 900$ bp region from the $5^{\prime}$ end of the insert in pLUC3.4 with EcoR1. pLUC1.3 was generated through partial digestion of pLUC2.5 with HindIII. An $\sim 1.7 \mathrm{~kb}$ fragment was then gel purified (Qiagen) and inserted into the HindIII site of an empty pGL4.14 vector. Primers containing Nhe1 and BglII restriction enzyme sites (Table 1) were used to PCR amplify the $\sim 1.3 \mathrm{kbp}$ fragment inside pLUC1.0. pLUC0.7 was produced by digesting pLUC1.0 with HindIII and inserting the fragment into the HindIII site in pGL4.14. pLUC0.6 was generated through PCR amplification of an $\sim 940$ bp region (Table 1) from the pLUC3.4 plasmid and subcloned into pCR2.1-TOPO. A $0.933 \mathrm{~kb}$ fragment was excised from this construct with EcoR1, blunted with Klenow fragments (Fermentas), and inserted into the blunted HindIII site in PGL4.14. To produce FLAGtagged Ngn2, the Ngn2 open reading frame was digested with EcoRI from PC1G2-Ngn2, and inserted into pcDNA3.1 FLAG (Invitrogen). pCDNA3.1/His-Ngn2 was produced by excising the Ngn2 open reading frame from PC1G2-Ngn2 with EcoRI and ligating into the same restriction site in pCDNA3.1/His (Invitrogen). All nucleotide mutations were generated using specific primers (Table 1) and the QuikChange Lightning Site Directed Mutagenesis Kit (Stratagene), according to the manufacturer's instructions. All insertions and orientations were verified through sequencing.

Transfections were performed using the LipofectAMINE 2000 reagent kit (Promega), as per manufacture's recommendation. Undifferentiated P19 cells $(70-80 \%$ confluent) were transfected with $1 \mu \mathrm{g}$ (Ngn2, NeuroD, or Mash1 cDNA containing constructs) or $12 \mu \mathrm{g}$ (promoterreporter or parental vector constructs) of plasmid DNA along with phRG-TK vector (Promega; used for transfection efficiency). Cells were harvested $24 \mathrm{~h}$ later or differentiated by treating with RA or DMSO for $4 \mathrm{~d}$ before harvesting. To determine reporter gene activity, transfected P19 cells were washed with cold $1 \times$ PBS, scraped, and lysed in $1 \times$ reporter lysis buffer followed by three freeze-thaw cycles. Extracts were centrifuged $\left(10,000 \times g\right.$ for $10 \mathrm{~min}$ at $\left.4^{\circ} \mathrm{C}\right)$, and the resulting supernatant was assayed using a Dual-Luciferase Reporter Assay kit (Promega) and Lumat AT 9507 luminometer (Berthold Technologies). Firefly luciferase activity was normalized to renilla (phRGTK) luciferase activity and expressed as fold activity over parental control.

In situ hybridization. Experiments were performed as previously described (Young and Chang, 1998) with minor modifications. Briefly, a cDNA fragment encoding HuD E1c was PCR amplified from P19 cells and subcloned into pCR4.0 TOPO plasmids (Invitrogen). Subsequently, the constructs were linearized with Pst1 or Not1 and used as templates for T7 or T3 RNA polymerase-mediated in vitro transcription of radiolabeled antisense and sense probes, respectively. Purified probes were stored at $-80^{\circ} \mathrm{C}$ until use. Mouse E14.5 embryos were cleared from the extra-embryonic membranes, then the heads were removed, fixed in RNase-free $4 \%$ paraformaldehyde (diluted in PBS) at $4^{\circ} \mathrm{C}$ overnight, and frozen in OCT at $-80^{\circ} \mathrm{C}$. For hybridization, $\sim 200,000 \mathrm{cpm} \mathrm{HuD} \mathrm{E1c}$ antisense and sense probes were placed on tissue sections and slides were subsequently developed 1-2 weeks later in Kodak Dektol developer. Slides were viewed and photographed using an Axiophot microscope (Carl Zeiss).

Electrophoresis mobility shift assay. EMSAs were conducted as previously described (Hellman and Fried, 2007). Briefly, Ngn2, E47, and LacZ recombinant proteins were produced using the TNT Quick Coupled Transcription/Translation Kit (Promega) from pCDNA3.1/His-Ngn2, pCDNA3-E47, and pCDNA3.1/myc-His/LacZ (Invitrogen), respectively, according to manufacturer's protocol. For production of the DNA probes, a $0.29 \mathrm{~kb}$ fragment was digested out of the pLUC1.0 and pLUC1.0M $2+3$ plasmids using Nhe1 and HindIII to obtain the wildtype and mutant sequences, respectively. DNA fragments were endlabeled with ${ }^{32} \mathrm{P} \gamma$-ATP (PerkinElmer) and T4 polynucleotide kinase (Fermentas). EMSAs reactions were performed by incubating $\sim 50,000$ cpm of labeled probe with $1.5 \mu \mathrm{l}$ of recombinant Ngn2, E47, and/or LacZ, $0.02 \mu \mathrm{g} / \mu \mathrm{l}$ salmon sperm, $1.25 \mu \mathrm{g} / \mu \mathrm{l}$ BSA, $1 \mathrm{~mm}$ DTT, $7.5 \mathrm{~mm}$ $\mathrm{MgCl}_{2}, 20 \mathrm{~mm}$ HEPES buffer, $0.2 \mathrm{~mm}$ EDTA, $0.1 \mathrm{M} \mathrm{KCl}$, and a proteinase inhibitor (Roche). For competition assays, a nonradioactive $0.29 \mathrm{~kb}$ fragment DNA was added in molar excess (5-10×) 10 min before adding radiolabeled DNA. The reactions were incubated for $1 \mathrm{~h}$ at $30^{\circ} \mathrm{C}$, resolved on non-denaturing $4.5 \%$ polyacrylamide gels, and exposed on BioMAX MR film (Eastman Kodak).

Chromatin immunoprecipitation. Chromatin immunoprecipitation (ChIP) experiments were performed as previously described (RavelChapuis et al., 2007), using the EZ-ChIP protocol (Millipore). Briefly, an empty plasmid (FLAG-Basic) and a plasmid containing Ngn2 cDNA (FLAG-Ngn2) were transfected into undifferentiated P19 cells. Twentyfour hours after transfection, cells were fixed for $1 \mathrm{~h}$ in $1 \%$ formaldehyde, washed, and resuspended in SDS lysis buffer. The lysate was sonnicated, incubated with $1 \mu \mathrm{g}$ of $\alpha \operatorname{IgG}$ (Santa Cruz Biotechnology), $\alpha$ FLAG (Sigma-Aldrich), or $\alpha$ POLII (a kind gift from Dr. Jocelyn Côté, University of Ottawa, Ottawa, ON, Canada) antibody overnight, and immunoprecipitated with Protein A/G PLUS beads (Santa Cruz Biotechnology). Immunoprecipitates were washed $5 \times$ and reverse crosslinked at $65^{\circ} \mathrm{C}$ for $4-5 \mathrm{~h}$. Following phenol/chloroform extraction, $\mathrm{qPCR}$ was performed with specific primers (Table 1) to identify regions of interest.

Statistical analysis. The data were analyzed using two-tailed Student's $t$ tests and the level of significance was set at $p<0.05$. Mean \pm SEM is presented throughout.

\section{Results \\ Neuron-specific expression of $\mathrm{HuD}$ is transcriptionally regulated}

Previous reports have shown that $\mathrm{HuD}$ is present at low levels in neuronal progenitors and some non-neuronal cells but that it is predominantly expressed in neurons (Okano and Darnell, 1997; Abdelmohsen et al., 2010). These findings indicate that developmentally early and cell-specific mechanisms govern expression of $\mathrm{HuD}$. To determine the pattern of cell-specific HuD expression during neurogenesis, we performed experiments with pluripotent embryonal teratocarcinoma P19 cells since they can be conveniently differentiated into neuronal or mesodermal lineages following treatment with all-trans RA or DMSO, respectively (McBurney et al., 1982).

In our first set of experiments, we determined the levels of $\mathrm{HuD}$ mRNA at different time points of P19 differentiation into neuronal and mesodermal lineages. Semiquantitative RT-PCR assays demonstrated that $\mathrm{HuD}$ transcripts were induced in differentiating neuronal cells, with highest expression observed at day 4 (Fig. $1 A$ ). In addition, we did observe a low level of $\mathrm{HuD}$ expression at different time points of mesodermal differentiation (Fig. 1A), which is in accordance with recent studies showing minor HuD abundance in skeletal muscle (Abdelmohsen et al., 2010). As a positive control for mesodermal differentiation, we also performed RT-PCR assays with Brachyury T primers, a transcription factor important for proper mesodermal development 

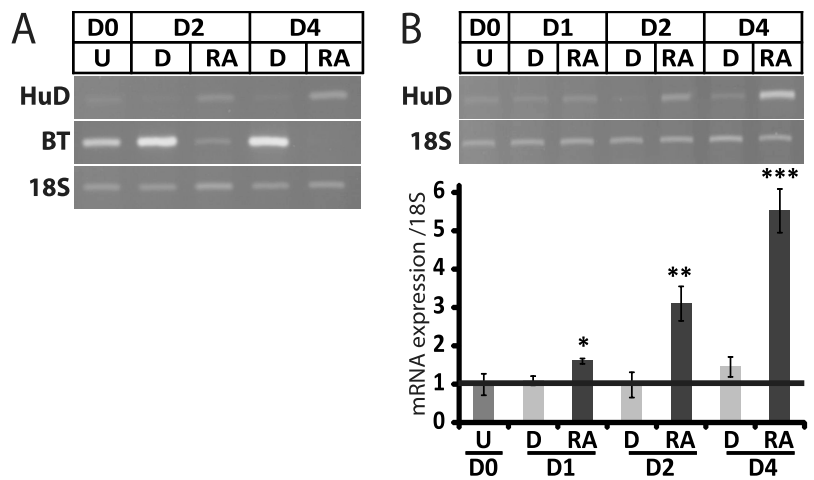
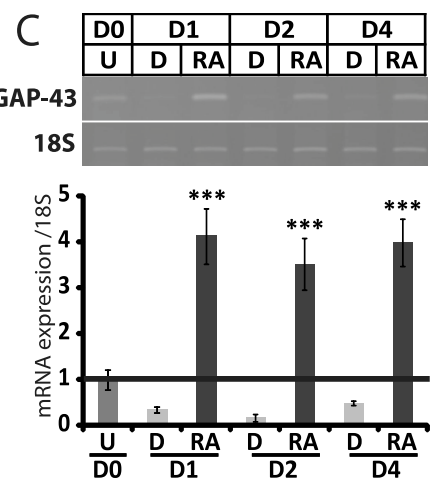
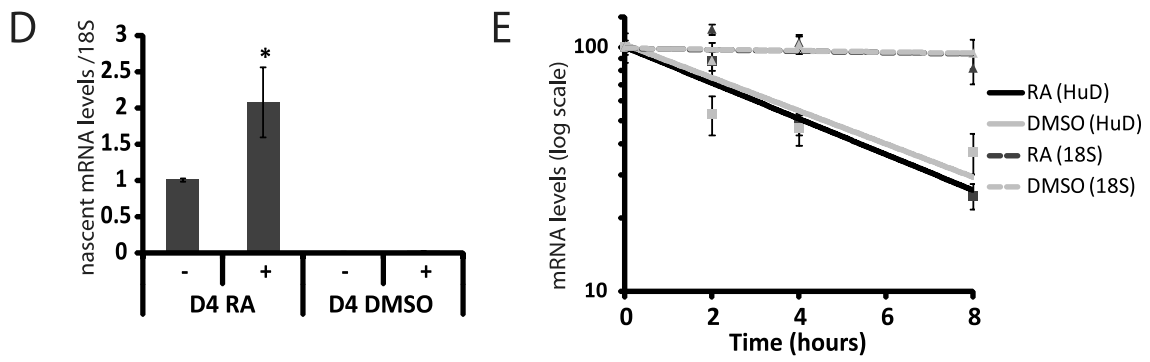

Figure 1. Neuron-specific HuD expression is transcriptionally regulated in differentiating P19 cells. $\boldsymbol{A}$, Ethidium bromide-stained 1.5\% agarose gels showing RT-PCR product intensity of HuD, Brachyury T (BT), and 18S transcripts during P19 cell differentiation. Top, Representative ethidium bromide-stained 1.5\% agarose gels and quantification (bottom) showing increased mRNA expression of total (all E1 isoforms) HuD (B) and GAP-43 ( $($ ) at different time points during P19 cell neuronal or mesodermal differentiation. ImageJ software (NIH) was used to quantify RT-PCR band intensities. Values were normalized over 18 S. Data are means \pm SEM, $n=3$. D, Nuclear run-on assay showing altered nascent HuD mRNA levels in neuronal and mesodermal P19 cells. Nuclei from neuronal and mesoderm cells were harvested and incubated in a transcription reaction mixture $(+)$ or vehicle $(-)$ (see Materials and Methods). Subsequently, endogenous HuD and $18 \mathrm{~S}$ levels were quantified using real-time quantitative RT-PCR (qPCR). Values were normalized over $18 \mathrm{~S}$. Data are means $\pm S E M, n=4$. E, Endogenous mRNA stability of HuD and $18 \mathrm{~S}$ transcripts in neuronal and non-neuronal cells. Four day neuron and mesoderm differentiated P19 cells were treated with Actinomycin D (4 $\mu \mathrm{g} / \mu \mathrm{l})$ for the indicated time points. Endogenous HuD mRNA expression was quantified using qPCR. Data are means $\pm \mathrm{SEM}, n=4 .{ }^{*} p<0.05 ;{ }^{* *} p<0.01 ;{ }^{* * *} p<0.001$ (Student's $t$ test).

(Showell et al., 2004), and found that it is highly expressed in mesoderm but barely detectable in neuronal P19 cells (Fig. 1A). These experiments validate $\mathrm{P} 19$ cells as a valuable model to define the mechanisms governing neuron-restrictive $\mathrm{HuD}$ expression during early development.

Quantification of mRNA expression during early P19 development revealed a significant increase in HuD transcript levels after $1 \mathrm{~d}$ of neurogenesis $(p<0.05)$, with the highest levels measured at $4 \mathrm{~d}(p<0.05)$, compared with undifferentiated cells (Fig. $1 B)$. As a positive control for neuronal differentiation, we also quantified expression of GAP-43 mRNA, a well known $\mathrm{HuD}$ mRNA target. A robust $(p<0.05)$ induction in GAP-43 transcripts was detected after $1 \mathrm{~d}$ of neuronal differentiation and its expression levels remained constantly high thereafter (Fig. 1C). The discordance between $\mathrm{HuD}$ and GAP-43 mRNA levels during early P19 neurogenesis (Fig. $1 B, C$ ) is likely a consequence of transcriptional activation of GAP-43 expression during early neurogenesis (Zhao et al., 2012).

Based on our finding that HuD transcript levels are upregulated only in neurons, we set out to determine whether this induction is dependent on transcriptional and/or post-transcriptional events. For this, we performed modified nuclear run-on assays using nuclei isolated from $4 \mathrm{~d}$ RA- (neuronal lineage) and DMSO- (mesodermal lineage) treated P19 cells. Our results demonstrate an increase in $\mathrm{HuD}$ mRNA levels in actively transcribing nuclei obtained from neuronal $(p<0.05)$ cells (Fig. $1 D)$. We also detected a small, although not significant $(p>0.05)$, augmentation in HuD mRNA synthesis in mesodermal cells (Fig. 1D), which could account for the low levels of $\mathrm{HuD}$ transcripts detected in these cells (Fig. 1A,B). These findings indicate that tran- scriptional mechanisms are at least partially responsible for the neuron-specific $\mathrm{HuD}$ induction.

Recent studies have demonstrated that the abundance of $\mathrm{HuD}$ mRNA is also subjected to post-transcriptional control by RBPs and at least one micro-RNA (Abdelmohsen et al., 2010; Bolognani et al., 2010). In view of these findings, and since we (Fig. $1 A, B)$ and others have detected basal $\mathrm{HuD}$ expression in nonneuronal cells, we decided to complement our transcription assays by determining whether $\mathrm{HuD}$ mRNA stability is also regulated in a cell-specific manner. To this end, we treated neuronal and mesodermal P19 cells with Actinomycin D and measured endogenous $\mathrm{HuD}$ mRNA levels at different time-points thereafter. Using this approach, we obtained analogous endogenous $\mathrm{HuD}$ mRNA half-lives in both cell types (neurons; $3.81 \pm$ $0.67 \mathrm{~h}$ and mesodermal cells; $4.00 \pm 1.00 \mathrm{~h} ; p>0.05)$, indicating that similar post-transcriptional mechanisms regulate $\mathrm{HuD}$ mRNA expression in developing neuronal and mesoderm cells (Fig. 1E). These results are comparable to the previously published half-life values of $\mathrm{HuD}$ obtained in embryonic stem cells (Sharova et al., 2009). To further investigate this issue, we generated chimeric HuD 3'UTR (accession number NM_010488; nucleotides 1613 to 3736) reporter constructs, transfected them into P19 cells, and measured luciferase activity following $4 \mathrm{~d}$ of neuronal or mesodermal differentiation. Our results revealed similar relative luciferase activity in both cell types [neurons $=3.17 \pm 0.43$ (arbitrary units) versus mesodermal cells $=2.31 \pm 0.31 ; p>0.05]$, thereby further indicating that $\mathrm{HuD}$ mRNA expression is primarily transcriptionally regulated in developing P19 neurons. 
Table 2. Refseq, EST, and Ensembl database accession numbers for HuD E1 variants

\begin{tabular}{|c|c|c|c|c|c|c|c|c|}
\hline & E1a & $\mathrm{E}_{1 \mathrm{a}^{1}}$ & $E 1 a^{2}$ & $\mathrm{E} 1 \mathrm{a}^{3}$ & $E 1 a^{4}$ & E1b & E1c & $\mathrm{E} 1 \mathrm{c}^{\mathrm{T}}$ \\
\hline RefSeq mouse mRNA & NM_001163397.1 & $\mathrm{n} / \mathrm{a}$ & $\mathrm{n} / \mathrm{a}$ & $\mathrm{n} / \mathrm{a}$ & $n / a$ & NM_001038698.1 & NM_001163399.1 & $n / a$ \\
\hline $\begin{array}{l}\text { Ensembl mouse } \\
\text { transcript \# (ID \#) }\end{array}$ & $\begin{array}{l}\text { Elavl4-001 } \\
\text { (ENSMUST00000106603) }\end{array}$ & $\begin{array}{l}\text { Elavl4-007 } \\
\text { (ENSMUST00000106601) }\end{array}$ & $\begin{array}{l}\text { Elavl4-008 } \\
\text { (ENSMUST00000142722) }\end{array}$ & $\begin{array}{l}\text { Elavl4-006 } \\
\text { (ENSMUST00000106600) }\end{array}$ & $\mathrm{n} / \mathrm{a}$ & $\begin{array}{l}\text { Elavl4-002 } \\
\text { (ENSMUST00000102723) } \\
\text { Elavl4-003 } \\
\text { (ENSMUST00000106598) } \\
\text { Elavl4-011 } \\
\text { (ENSMUST00000153906) }\end{array}$ & $\begin{array}{l}\text { Elavl4-004 } \\
\text { (ENSMUST00000106597) } \\
\text { Elav14-005 } \\
\text { (ENSMUST00000102722) } \\
\text { Elavl4-012 } \\
\text { (ENSMUST00000138972) }\end{array}$ & $\begin{array}{l}\text { Elav|4-010 } \\
\text { (ENSMUSG00000028546) }\end{array}$ \\
\hline Mouse ESTs & $\begin{array}{l}\text { C0432423 } \\
\text { CX217483 } \\
\text { CF726962 }\end{array}$ & $\mathrm{n} / \mathrm{a}$ & $\begin{array}{l}\text { BY095572 } \\
\text { BY077759 } \\
\text { BY277368 } \\
\text { BY279276 }\end{array}$ & 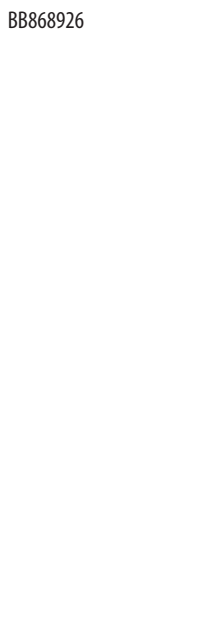 & JX178292 & $\begin{array}{l}\text { BU701986 } \\
\text { BG807610 } \\
\text { BQ769443 } \\
\text { CD776418 } \\
\text { BU057510 } \\
\text { BG807621 } \\
\text { B1985239 } \\
\text { BU920121 } \\
\text { BB626228 } \\
\text { B1991095 } \\
\text { BU918620 } \\
\text { BG804672 } \\
\text { BG807880 } \\
\text { CN663544 } \\
\text { W18631 } \\
\text { CA329034 } \\
\text { BE653746 } \\
\text { BY789145 } \\
\text { BB872444 } \\
\text { BB873655 }\end{array}$ & $\begin{array}{l}\text { CA527274 } \\
\text { CJ056024 } \\
\text { BQ770553 } \\
\text { BB626275 } \\
\text { BY274447 } \\
\text { BB648788 } \\
\text { BY290872 } \\
\text { CJ133636 } \\
\text { CD552588 } \\
\text { BP769869 } \\
\text { BB869084 }\end{array}$ & DQ437511.1 \\
\hline RefSeq human mRNA & NM_001144777.1 & NM_001144776.1 & $\mathrm{n} / \mathrm{a}$ & NM_001144775.1 & $\mathrm{n} / \mathrm{a}$ & $\begin{array}{l}\text { NM_001144774.1 } \\
\text { NM_021952.3 }\end{array}$ & $\mathrm{n} / \mathrm{a}$ & $\mathrm{n} / \mathrm{a}$ \\
\hline $\begin{array}{l}\text { Ensembl human } \\
\text { transcript \# (ID \#) }\end{array}$ & $\begin{array}{l}\text { Elavl4-201 } \\
\text { (ENST00000448907) }\end{array}$ & $\begin{array}{l}\text { Elavl4-001 } \\
\text { (ENST00000371827) }\end{array}$ & $\mathrm{n} / \mathrm{a}$ & $\begin{array}{l}\text { Elavl4-002 } \\
\text { (ENST00000357083) }\end{array}$ & $\mathrm{n} / \mathrm{a}$ & $\begin{array}{l}\text { Elavl4-004 } \\
\text { (ENST00000371823) } \\
\text { Elav14-003 } \\
\text { (ENST00000371824) }\end{array}$ & $\begin{array}{l}\text { Elavl4-005 } \\
\text { (ENST00000371821) } \\
\text { Elav14-006 } \\
\text { (ENST00000371819) }\end{array}$ & $\mathrm{n} / \mathrm{a}$ \\
\hline Human ESTs & $\begin{array}{l}\text { DC351092 } \\
\text { DA904958 } \\
\text { AL525200 } \\
\text { BX386941 }\end{array}$ & $\mathrm{n} / \mathrm{a}$ & $\mathrm{n} / \mathrm{a}$ & $\begin{array}{l}\text { BM509527 } \\
\text { BQ267762 }\end{array}$ & $\mathrm{n} / \mathrm{a}$ & $\begin{array}{l}\text { CK005107 } \\
\text { DB472040 } \\
\text { DC360842 } \\
\text { DC361109 } \\
\text { DC337942 } \\
\text { DC352242 } \\
\text { DC360175 } \\
\text { B1604034 } \\
\text { DB501125 } \\
\text { AL530909 } \\
\text { AU100542 }\end{array}$ & $\begin{array}{l}\text { DC367063 } \\
\text { DC363892 } \\
\text { BM693606 } \\
\text { BI914284 } \\
\text { DC366017 } \\
\text { AA214645 } \\
\text { DC338260 } \\
\text { BP192961 } \\
\text { DC365508 } \\
\text { BX464139 } \\
\text { AW965319 } \\
\text { BX282543 } \\
\text { DN993403 } \\
\text { BM928123 } \\
\text { BM928402 } \\
\text { BP193370 } \\
\text { BM711406 } \\
\text { BM716630 } \\
\text { DA608723 } \\
\text { AA161265 }\end{array}$ & $\mathrm{n} / \mathrm{a}$ \\
\hline
\end{tabular}

Published Refseq (www.ncbi.nlm.nih.gov/RefSeq/), EST (www.ncbi.nlm.nih.gov/dbEST/), and Ensembl (www.ensembl.org/) database accession numbers for all eight mouse and human HuD 5' mRNA variants.

The HuD 5' genomic region contains eight E1 variants

Although the $5^{\prime}$ end of the mammalian $H u D$ gene is relatively uncharacterized, one previous study identified three noncoding exon 1 variants (E1a, E1b, and E1c) upstream of E2 by aligning available mouse mRNA sequences (Inman et al., 1998). To gain further insight into HuD E1 variants, we searched the NCBI RefSeq database (http://www.ncbi.nlm.nih.gov/RefSeq) and spliced expressed sequence tags (ESTs) listed in the USCS genome browser (http://genome.ucsc.edu/) for related mouse and human sequences. Interestingly, alignment of existing $\mathrm{HuD}$ mRNA sequences (see Table 2 for accession numbers) with the mouse $\mathrm{HuD}$ $5^{\prime}$ genomic flanking region revealed six distinct $5^{\prime}$ ends, provid- ing additional evidence that multiple leader exons exist. To determine whether these E1 variants are expressed in developing mouse neurons, 5'RACE experiments were conducted using RNA from $4 \mathrm{~d}$ differentiated P19 neurons. Using a $\mathrm{HuD}$ exon 2-specific reverse primer, we obtained a diverse range (50-400 bp) of PCR products, which were subsequently subcloned and sequenced. Alignment of 5'RACE clones with the available leader exons unveiled two novel HuD E1 splice variants $\left(\mathrm{E} 1 \mathrm{a}^{4}\right.$ and E1c ${ }^{1}$; Table 2). These eight leader exons were mapped onto the $H u D$ gene locus and named in accordance with the previously sug-

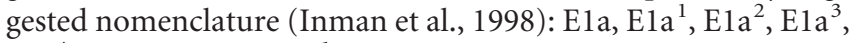
E1a ${ }^{4}$, E1b, E1c, and E1c ${ }^{1}$ (Fig. 2A). 


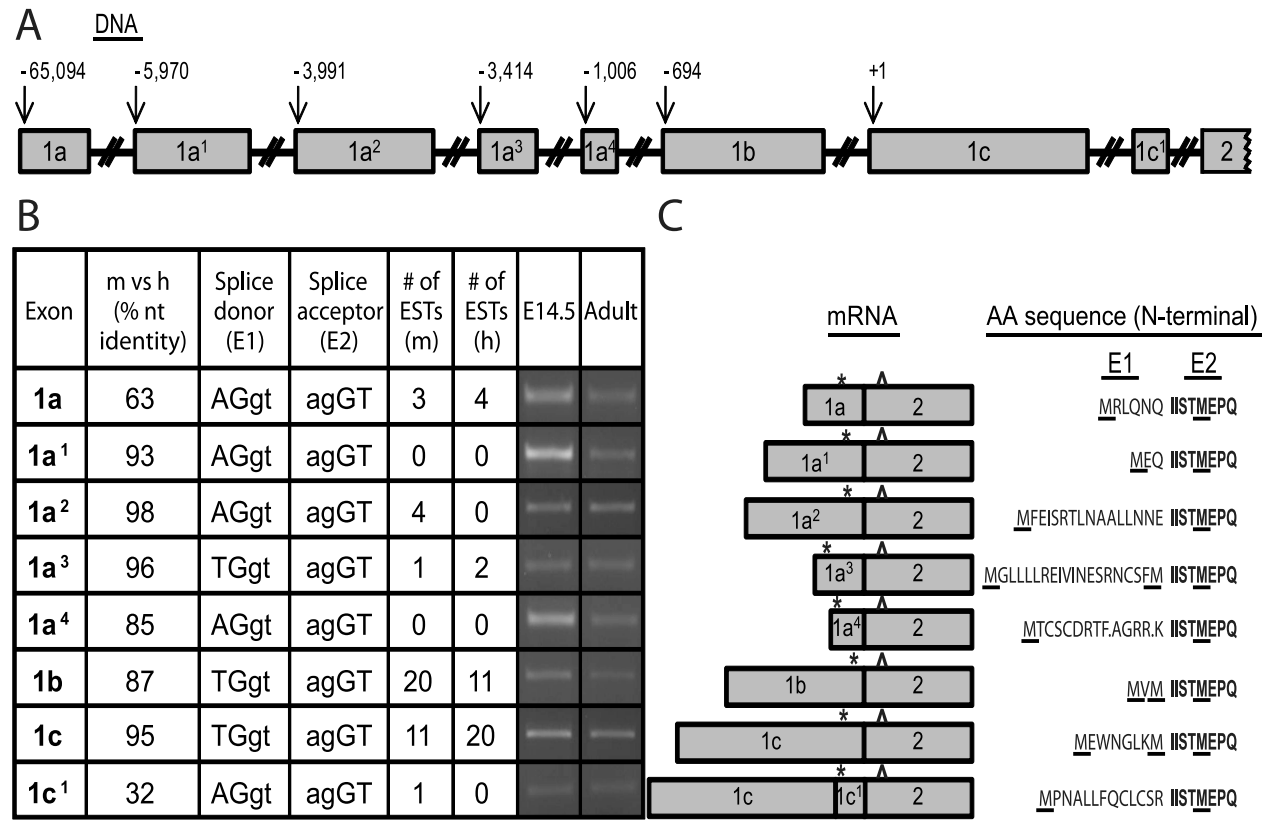

Figure 2. The HuD 5'RR contains eight alternative E1 variants. $\boldsymbol{A}$, Schematic diagram illustrating the genomic organization of HuDE1 splice variants and their TSS relative to the TSS of E1c. $\boldsymbol{B}$, Table showing the percentage identity between mouse $(\mathrm{m})$ and human $(\mathrm{h})$ sequences, the splice donor/acceptor sites, and the known number of mouse and human ESTs for each leader exon. Also displayed are representative ethidium bromide-stained 1.5\% agarose gels showing the RT-PCR product for each E1 variant in embryonic (E14.5) and adult (2 months) mouse brain. C, Schematic demonstrating alternative splicing of each E1 variant to a common E2, the favored $(\wedge)$ versus putative alternate $\left({ }^{*}\right.$ ) translation start site (AUG) and the possible alternate $\mathrm{N}$-terminal amino acid (AA) sequences encoded by each 11 variant. Methionines $(M)$ are underlined and dots (.) represent putative stop codons. Identification of E1 variants is based on $5{ }^{\prime}$ RACE assays and bioinformatic analysis.

Examination of the exon/intron boundaries revealed the presence of canonical splice donor sites at the $3^{\prime}$ end of each exon (Fig. $2 B$ ). Moreover, sequencing of RACE clones showed that each E1 variant was individually spliced to a common E2. The only exemption from this was E1 $c^{1}$, which was found spliced in between E1c and E2 (Fig. 2C). Interspecies nucleotide sequence comparison demonstrated that most E1 variants were highly conserved $(>85 \%)$ between mouse and humans except for E1a and E1c ${ }^{1}$, which were also conserved but to a lesser degree (Fig. $2 B$ ). Interestingly, all E1 isoforms contain an in-frame translation initiation codon (ATG), which raises the possibility that these exons encode alternate N-terminals of the HuD protein (Fig. 2C). The exception to this is $\mathrm{E}^{4} \mathrm{a}^{4}$, since it contains two stop codons downstream of the AUG (Fig. 2C). Collectively, these results demonstrate that the mammalian $H u D$ gene contains eight conserved leader exons, indicative of complex transcriptional regulation and alternate $5^{\prime}$ ends in HuD transcripts.

We confirmed expression of all eight E1 variants by RTPCR on RNA samples from embryonic (E14.5) and adult murine brains (Fig. $2 B$ ). Analysis of the mouse and human spliced EST sequences suggested that E1c, along with E1b, are two of the most abundant HuD E1 variants (Table 2). Importantly, absolute expressions levels of the leader exons expressed in adult murine brain also indicated that E1c is one of the major E1 variants expressed. In agreement with this, we found that the majority $(74 \%)$ of 5 'RACE products encoded E1c (Fig. $2 B$ ). Based on these findings, we focused hereafter on characterizing the expression pattern and regulation of E1ccontaining $\mathrm{HuD}$ transcripts.

Spatial and temporal expression of the E1c variant

To determine cell-type specific expression of E1c-containing $\mathrm{HuD}$ mRNAs in neurons, we performed semiquantitative RTPCR with exon-specific forward primers and a common E2 re- verse primer. The abundance of $\mathrm{HuD}$ mRNAs containing E1c significantly increased after $1 \mathrm{~d}$ of neuronal differentiation $(p<$ $0.05)$, with the highest levels measured at day $4(p<0.05)$ (Fig. $3 A$ ). Notably, this pattern of expression parallels that of total (all isoforms) $\mathrm{HuD}$ mRNA (Fig. $1 B$ ). No changes in $\mathrm{HuD}$ E1cbearing transcript levels were detected during mesodermal P19 differentiation (Fig. 3A).

Subsequently, we set out to establish the pattern of E1c expression in mouse embryonic (E14.5) and adult ( $\sim 6$ weeks) brains. Similar levels of E1c-bearing mRNA abundance were found in embryonic and adult brains, whereas no expression was detected in adult skeletal muscle (used as a control; Fig. $3 B$ ). These in vivo results parallel our cell culture findings, which show that E1c is highly abundant in neuronal cells but is barely expressed or not detectable in a mesodermal lineage.

To examine the spatial distribution of $\mathrm{HuD}$ E1c-containing mRNAs in mouse embryonic brain, we performed in situ hybridization experiments with probes specific to E1c. Dispersed expression of E1c was observed at E14.5 throughout the brain, including the developing amygdala, hippocampus, and cerebral cortex (Fig. 3C). In addition, we detected strong expression of E1c in the olfactory bulb and retina (Fig. $3 C$ ). The localized expression of E1c-containing transcripts in the embryonic brain parallels the previously reported expression of total (all isoforms) $\mathrm{HuD}$ mRNA, indicating that E1c is present in most, if not all, $\mathrm{HuD}$-expressing neurons in the developing brain (Okano and Darnell, 1997; Clayton et al., 1998).

\section{Identification of functional regulatory regions upstream of E1c}

Next, we wanted to determine whether the HuD E1c 5 ' regulatory region $(\mathrm{RR})$ contains a functional promoter and cis-elements that regulate neuron-specific expression. For this purpose, we first analyzed and aligned the mouse and human genomic se- 
A
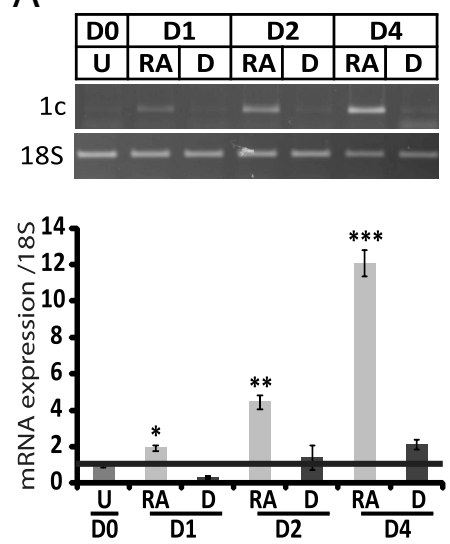

B
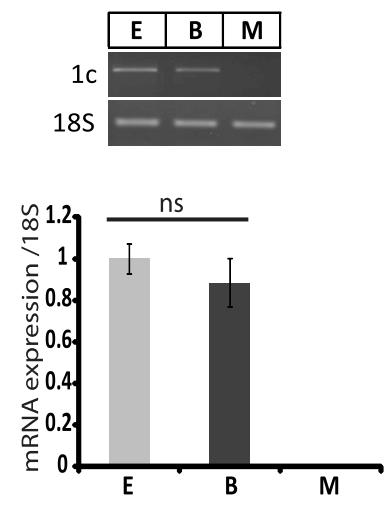
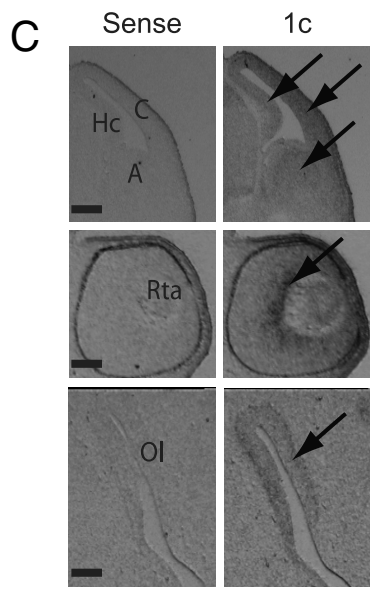

Figure 3. Expression profile of E1c-containing transcripts in differentiating P19 cells, developing mouse brain, and mouse skeletal muscle. Top, Ethidium bromide-stained 1.5\% agarose gels showing RT-PCR product intensity of the E1c variant and $18 \mathrm{~S}$ at different stages of P19 cell differentiation $(\boldsymbol{A})$ and mouse brain development $(\boldsymbol{B})$. Primers spanning the E1c-E2 boundary of HuD mRNA were used for PCR amplification. Bottom, Graphs representing quantified (ImageJ) RT-PCR products. Data are means \pm SEM, $n=3 .{ }^{*} p<0.05 ;{ }^{* *} p<0.01$; ${ }^{* * *} p<0.001 ; \mathrm{ns}, p>0.05$ (Student's $t$ test). E, Embryonic 14.5 brain; $B$, adult brain; and M, adult skeletal muscle. C, In situ hybridization using a $S^{35}$ radiolabeled RNA probe against E1c on coronal sections of embryonic day 14.5 mouse head (C57BL/6). Representative micrographs showing hybridization of HuD exon 1c sense and antisense probes on E14.5 mouse midbrain sections. Arrows point to cerebral cortex (C), hippocampus (Hc), amygdala (A), retina (Rta) and olfactory tract (Ol). Scale bars: top two panels, $400 \mu \mathrm{m}$; bottom four panels, $100 \mu \mathrm{m}$.

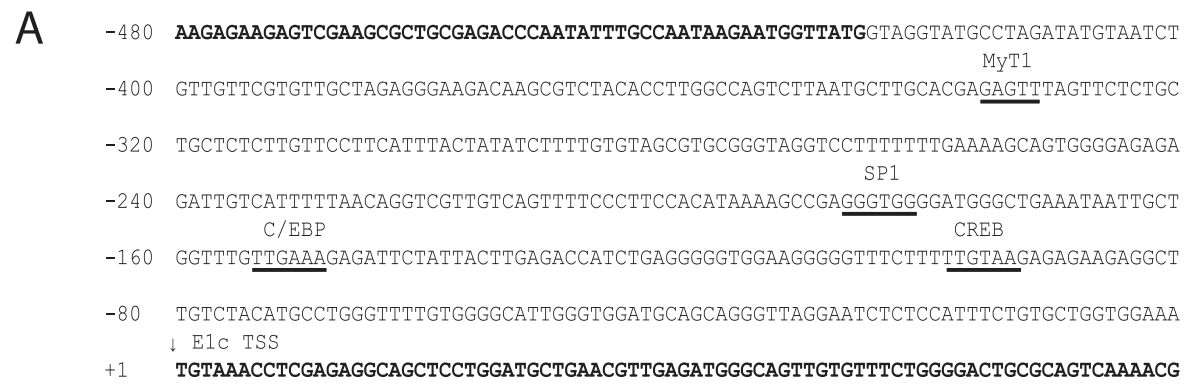

B

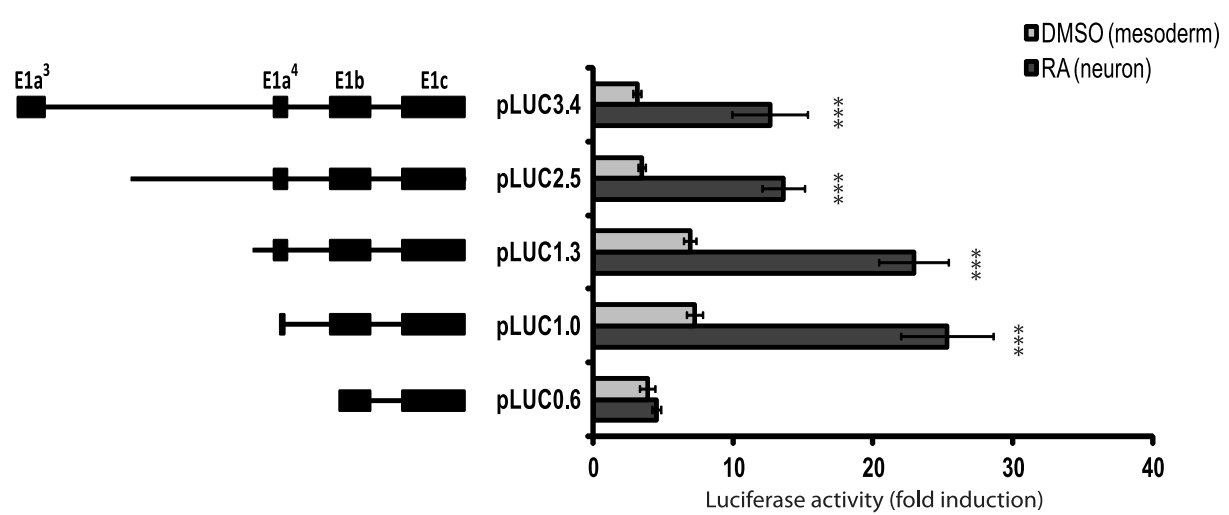

Figure 4. A 400 bp promoter region enhances HuD expression specifically in P19 neurons. $A$, Part of the mouse E1c $5^{\prime}$ RR sequence showing putative transcription factor binding sites and exon boundaries (bold). B, Left, Schematic representation of different sized E1 C 5 'RR fragments that were used for promoter reporter assays. Right, Luciferase activity produced by various sized E1 $55^{\prime}$ RR fragments in neuron (RA) and mesoderm (DMSO) differentiated P19 cells, standardized to parental Renilla activity (phRGTK). Data are means \pm SEM, $n=4 .{ }^{* * *} p<0.001$ (Student's $t$ test).

quences proximal to E1c using the MatInspector (Genomatix) (Cartharius et al., 2005) and Evolutionary Conserved Region browser (Ovcharenko et al., 2004) softwares. A high degree of nucleotide homology was found in several regions, suggesting the presence of functionally conserved regulatory elements. Since E1c is one of the most expressed E1 variants, its putative transcription start site (TSS) was numbered +1 based on the longest exon sequence obtained in our 5'RACE, and the surrounding nucleotides were numbered accordingly (Fig. 4A). Although no consensus cis-elements (i.e., TATA box) were found in the E1c putative core promoter, a few conserved putative binding sites in the proximal promoter region were identified, including CREB $(-93 /-98)$, C/EBP $(-148 /-154)$, Sp1 $(-181 /-187)$, and MyT1 (-321/-326; Fig. 4A).

To assess whether the region upstream of E1c contains a functional neuron-specific promoter and/or cis-regulatory elements, luciferase promoter-reporter constructs harboring different length fragments of E1c and its putative upstream regulatory region were generated (Fig. $4 B$ ). These constructs were transiently transfected into undifferentiated P19 cells and the cells 
were then simultaneously differentiated into neuronal and mesodermal lineages. Initially, we isolated and tested an $\sim 3.7 \mathrm{~kb}$ fragment (pLUC3.4; - 3414/+328) of the E1c 5' RR and found that it produced significantly higher reporter activity $(p<0.05)$ in P19 neurons compared with mesoderm (Fig. $4 B$ ). To locate a regulatory region that restricts $\mathrm{HuD}$ expression to neurons, we created successive $5^{\prime}$ deletion fragments of the pLUC3.4 construct, resulting in pLUC2.5 $(-2514 /+328)$, pLUC1.3 $(-1342 /$ +328), pLUC1.0 $(-1002 /+328)$, and pLUC0.6 $(-606 /+328)$. The former three constructs also significantly increased $(p<$ $0.05)$ luciferase activity specifically in neuronal versus mesoderm cells, with pLUC1.0 producing the greatest increase (Fig. $4 B$ ). Conversely, the pLUC0.6 construct generated similar levels of luciferase activity in both neuron and mesoderm cells $(p<0.05)$, suggesting that this promoter fragment lacks the cis-elements required to induce $\mathrm{HuD}$ expression specifically in neuronal cells (Fig. $4 B$ ). In these experiments, pLUC1.0 produced higher reporter activity in neuronal compared with mesodermal cells, whereas pLUC0.6 generated similar reporter activity in both cell types. These findings therefore indicate that the $\sim 400$ bp region $(-1002 /-606)$ contains cis-elements that promote neuron-specific transcription of the $\mathrm{HuD}$ E1c variant.

To identify potential transcription factor binding sites within the 400 bp fragment, we conducted in silico analysis with the MatInspector software. Examination of this region revealed a high degree of conservation among vertebrates (93\%) and the presence of several putative cis-elements (Fig. 5A). We sorted through the list of putative motifs and filtered out nontargets of documented neuron-specific regulators to narrow possible candidates. The most notable cis-elements included five putative E-box sequences, E-box 5 (-994/-988), E-box 4 (-810/-804), E-box $3(-756 /-750)$, E-box $2(-749 /-743)$, and E-box 1 $(-685 /-679)$, four of which are highly conserved among vertebrates (Fig. 5A).

Subsequently, we set out to identify trans-factors that bind to these E-boxes. In neurons, the E-box motif is a target of proneural basic helix loop helix (bHLH) transcription factors (TFs), such as Ngn, NeuroD, and Mash family members (for review, see Bertrand et al., 2002). Each TF displays preference for specific E-boxes, particularly the two central nucleotides in the hexamer sequence, onto which they typically heterodimerize with E-proteins (Seo et al., 2007). To initially test whether bHLH transcription factors can trans-activate $\mathrm{HuD}$ transcription via these five E-boxes, luciferase activity was examined following overexpression of full-length cDNAs of Mash1, NeuroD, or Ngn2 in undifferentiated P19 cells. Cotransfection with plasmids containing the cDNA of a bHLH heterodimerizing partner was not performed because some cofactors (i.e., E47) are already abundant in P19 cells (Kim et al., 2004). For these experiments, we tested the pLUC1.3 construct since it contains the $400 \mathrm{bp}$ region and similarly promotes higher reporter activity in neurons compared with mesoderm P19 cells (Fig. 4B). Our results revealed that overexpression of Mash 1 did not modulate luciferase expression $(p>0.05)$, whereas overexpression of NeuroD generated a small but significant increase in reporter activity $(p<0.05)$, compared with control (Fig. 5B). Remarkably, the largest increase in luciferase activity $(\sim 2.5 \times ; p<0.05)$ was observed following Ngn2 overexpression (Fig. 5B).

\section{Ngn2 promotes HuD transcription through two E-boxes upstream of E1c}

Ngn2 belongs to the Ngn family (1/2/3) of TFs and plays a central role in neuronal commitment, specification, and differentiation (for review, see Guillemot, 2007). To determine the Ngn2targeted motifs upstream of E1c, we first tested the ability of Ngn2 to increase endogenous $\mathrm{HuD}$ mRNA expression. To this end, we transiently transfected a construct harboring the full-length Ngn2 cDNA into undifferentiated P19 cells and harvested global RNA for RT-PCR analysis the next day. As expected based on our reporter assays results (Fig. $5 B$ ), overexpression of Ngn2 increased endogenous $\mathrm{HuD}$ mRNA levels (Fig. $5 C$ ).

To determine which of the 5 E-boxes in the 400 bp region upstream of E1c are putative targets of Ngn2, we screened their hexamer sequences for Ngn2 consensus motifs. Both E-boxes 2 and 3 contained the preferential motifs bound by Ngn2 (Fig. 5A). Accordingly, we examined whether these two motifs are necessary for Ngn2-mediated reporter activity by transfecting promoter-reporter constructs containing mutated or deleted E-boxes 2 and 3 in parallel with a Ngn2 (PC1G2:Ngn2) or a parental plasmid (PC1G2) into P19 cells (Fig. $5 D, E$ ). In agreement with our previous reporter assays (Fig. $4 B$ ), the wild-type pLUC1.0 construct containing the 400 bp region generated a significant $(p<0.05)$ increase in luciferase activity in the presence of exogenous Ngn2, compared with control (Fig. 5D). On the other hand, mutating either E-box 2, 3, or both (pLUC1.0M2, pLUC1.0M3 and pLUC1.0M2 + 3, respectively), or deletion of the region containing these two E-boxes (pLUC0.7), completely prevented the induction of relative luciferase activity observed following Ngn2 overexpression (Fig. 5D). Collectively, these studies indicate that Ngn2 can promote HuD E1c transcription by acting through two tandem E-boxes.

Next, we used two parallel methods to examine the interaction of Ngn 2 to E-boxes 2 and 3. In the first approach, electrophoresis mobility shift assays were conducted. A 291 bp probe $(-1002 /$ -711) was generated and incubated with in vitro transcribed/ translated Ngn2 and/or its cofactor E47. The formation of a major complex on the gel was only observed when the probe was incubated with both recombinant Ngn2 and E47 (Fig. 6A, lane 4). An additional, slower migrating, complex was detected when recombinant E47, but not Ngn2, was incubated alone with the probe (Fig. 6A, lane 3 ). This result is in agreement with the previous finding showing that $\mathrm{E} 47$ proteins can homodimerize on E-box motifs (Shen and Kadesch, 1995). Complex formation with Ngn2-E47 was concentration dependent (Fig. 6A, lanes $4-6)$ and could be reduced by adding a cold probe competitor (Fig. 6A, lanes 7-8). Moreover, mutation of E-boxes 2 and 3 completely abolished complex formation with Ngn2 and E47, further demonstrating the specificity of Ngn2 for these two E-boxes (Fig. 6A, lane 9-11).

In our second approach, we determined whether Ngn2 is recruited to the DNA region containing E-boxes 2 and 3 in vivo. For this, chromatin immunoprecipitation experiments were performed in undifferentiated P19 cells transiently transfected with a construct containing a FLAG-tagged Ngn2 cDNA or a control vector. Our results revealed increased binding to the DNA region containing both E-boxes $(p<0.05)$, but not to a nonspecific region $(\beta$-RARE; $p>0.05)$, in cells overexpressing the Ngn2 transgene (Fig. $6 B$ ). We also detected an $\sim 2 \times$ enrichment, although not significant $(p>0.05)$, of RNA polymerase II binding to the same region in P19 cells overexpressing Ngn2 (Fig. 6B). Together, these findings show that the Ngn2-E47 heterodimer binds to two E-boxes upstream of E1c both in vitro and in vivo to promote $\mathrm{HuD}$ transcription. 

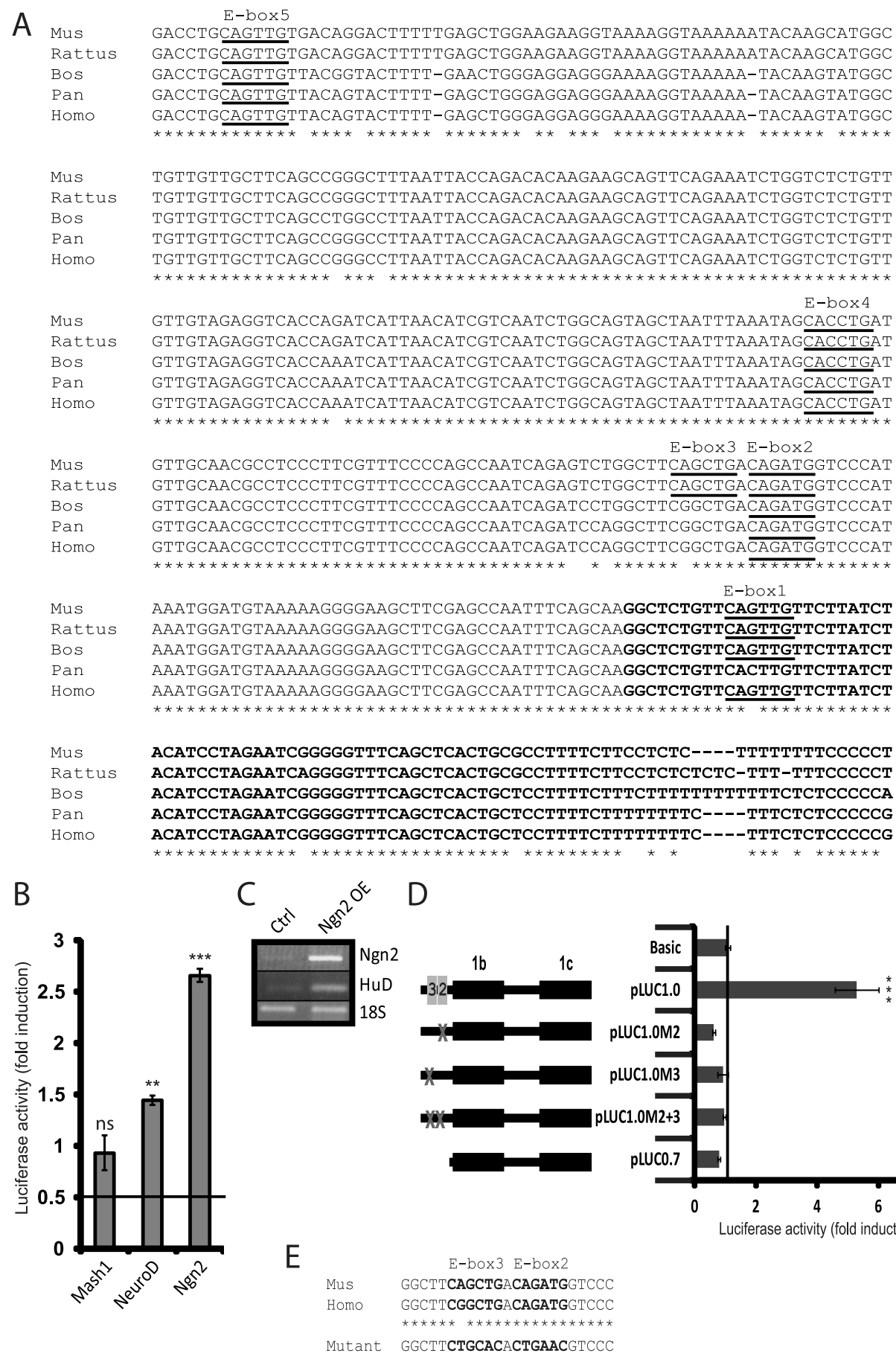

Figure 5. Ngn2 promotes reporter activity via two E-boxes in the HuD E1C 5'RR. A, Alignment of the mouse, rat, cow, monkey, and human $\sim 400$ bp DNA sequences upstream of E1c $(-1002 /-606)$ with putative E-boxes (underlined) and $5^{\prime}$ end of E1b (bold). Asterisk represents nucleotide conservation among all species. $\boldsymbol{B}$, Relative luciferase activity produced by promoterreporter constructs harboring an $\sim 1.3 \mathrm{~kb}$ fragment of the E1c $5^{\prime}$ RR region (pLUC1.3) following overexpression of Mash1, NeuroD, or Ngn2 in P19 cells. Values were standardized to Renilla luciferase promoter (phRG) activity. Data are means \pm SEM, $n=3$. C, Overexpression of Ngn2 (Ngn2 OE; PC1G2:Ngn2) in undifferentiated P19 cells increases endogenous HuD mRNA expression, compared with parental control (Ctrl; PC1G2). Data are means \pm SEM, $n=3$. D, Relative luciferase activity produced by promoter-reporter constructs harboring different fragments and sequence mutations of the E1C 5'RR region in Ngn2 (PC1G2:Ngn2), or parental vector (PC1G2), overexpressing P19 cells. Values were standardized to Renilla luciferase activity (phRGTK). Data are means \pm SEM, $n=$ $3 .{ }^{* *} p<0.01 ;{ }^{* * *} p<0.001 ; n s, p>0.05$ (Student's t test). E, Alignment of mouse and human E-boxes 2 and 3 wild-type and mutated sequences. Mus, Mus musculus; Rattus, Rattus norvegicus; Bos, Bos taurus; Pan, Pan paniscus; Homo, Homo sapiens.

\section{Discussion}

Despite its multifunctional roles in regulating mRNA metabolism, including processing, stability, and translation, the molecular mechanisms that govern mammalian $\mathrm{HuD}$ mRNA expression remain largely unexplored. Nevertheless, a few studies have uncovered transcriptional and post-transcriptional events that so far have only been shown to negatively control $\mathrm{HuD}$ transcript levels (Cuadrado et al., 2003; Abdelmohsen et al., 2010; Lee et al., 2012). In light of the key roles of $\mathrm{HuD}$ in developing and mature neurons, its implications in learning and memory as well as its involvement in several neurological diseases, it appears crucial to define the molecular machinery that promotes HuD expression. 


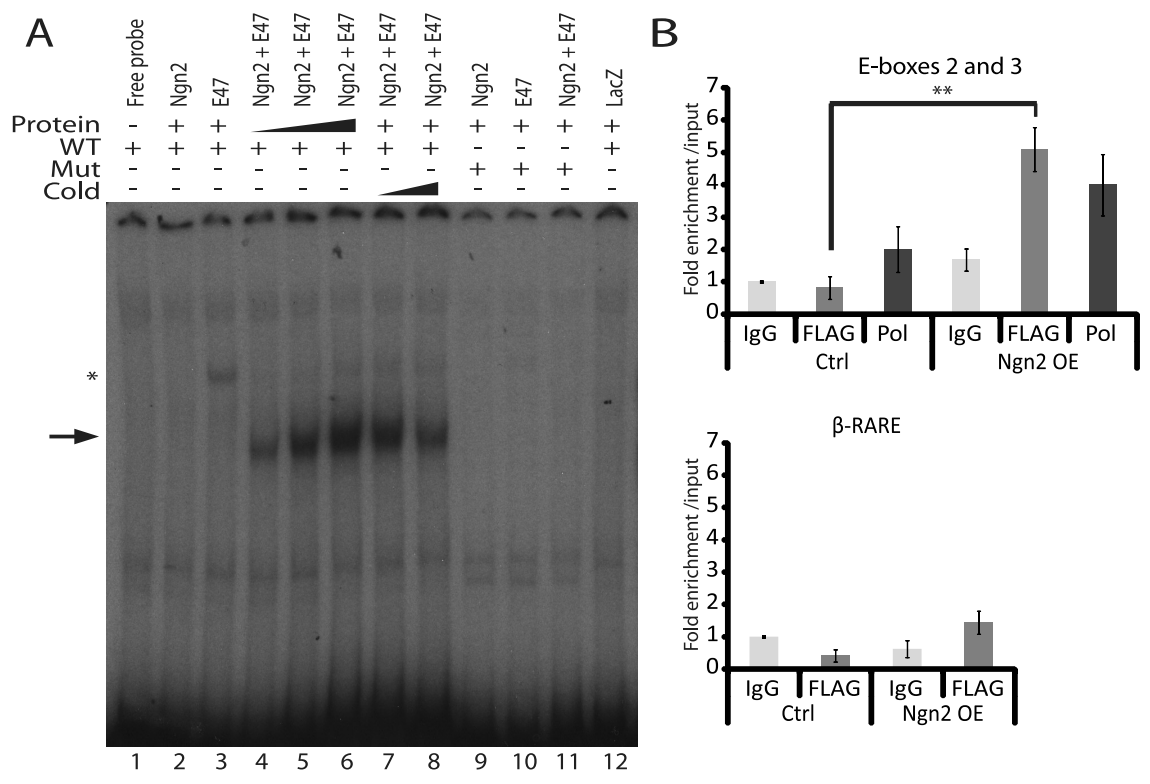

Figure 6. Ngn2-E47 heterodimer binds to E-boxes 2 and 3. A, Representative image of an EMSA gel showing that Ngn2-E47 heterodimers (lanes 4-6), but not Ngn2 alone (lane 2), can bind to E-boxes 2 and 3. This interaction is specific as shown through sequence mutation (lanes 9-11), addition of nonspecific protein (lane 12), and addition of 5-10× molar excess of a cold probe (lanes 7-8). Arrow points to the Ngn2-E47 heterodimer and asterisk indicates the E47 homodimers. $n=5$. B, Results from ChIP assays showing occupancy of the DNA region harboring E-boxes 2 and 3 in FLAG-tagged Ngn2 (Ngn2 OE) or parental plasmid (Ctrl) overexpressing cells. Immunoprecipitations were performed with anti-control (IgG), tag (FLAG), or RNA Polymerase II (Pol) antibodies. The $\beta$-RARE site was used as a negative control. Data are means $\pm \mathrm{SEM}, n=3 .{ }^{* *} p<0.01$ (Student's $t$ test).

Here, we characterized the $5^{\prime}$ genomic region of the $H u D$ gene and identified eight conserved alternate leader exons, with predominant expression of the E1c variant. Moreover, we examined neuronspecific $\mathrm{HuD}$ mRNA regulation and find that $\mathrm{HuD}$ expression is under Ngn2-dependent transcriptional control in developing neurons. To our knowledge, this is the first study to describe a molecular mechanism that positively regulates $\mathrm{HuD}$ expression.

Through bioinformatics and 5'RACE analysis, we found that the $H u D$ gene contains eight alternate leader exons in its $5^{\prime}$ genomic region, most of which are conserved among higher mammals. All of these exons are induced during P19 neurogenesis and are expressed in embryonic and adult brains. The identification of multiple E1 variants is coherent with the fact that the $5^{\prime}$ genomic region of mammalian $\mathrm{HuD}$ is very large, spanning $\sim 100 \mathrm{~kb}$ of DNA. Examination of the $5^{\prime}$ flanking genomic region of elrD, the HuD homolog in Xenopus, showed that it also contains multiple E1 variants (Nassar and Wegnez, 2001). The elrD leader exons, E1 and E'1, partially align with mouse E1b and E1c, implying that these two variants have evolutionarily conserved functional importance.

The presence of multiple leader exons raises questions regarding their expression and function. Expression of E1 variants is often a result of cell-type specific alternate promoter usage, which suggests that the HuD E1 variants may be under neuron-, and possibly neural subtype-, specific transcriptional control (Jacox et al., 2010). In the current study, we show that all eight E1 variants are expressed in embryonic (E14.5) and adult mouse brain, but at different levels. Analysis of the E1 sequences revealed that all variants encoded a conserved in-frame methionine upstream of the putative AUG in E2, suggesting that most of these E1s may encode a unique $\mathrm{HuD} \mathrm{N}$-terminal. In support of our results, the two E1 variants of elrD were also found to contain in-frame translation start sites that could potentially produce two different $\mathrm{N}$ termini (Nassar and Wegnez, 2001). Alternate $\mathrm{N}$ termini may be involved in subcellular localization and function of proteins as previously described for the Drosophila HuD homolog, ELAV (Yannoni and White, 1999), and other neuronal proteins (Meshorer et al., 2004; Turner et al., 2010).

A combination of experiments, namely 5'RACE, E1 absolute expression, and EST analysis, indicated that E1c is a principal variant expressed in neurons. Our results also demonstrated that spatial and temporal E1c-containing $\mathrm{HuD}$ mRNA expression parallels that of total (all isoforms) HuD transcripts. For example, pronounced total $\mathrm{HuD}$ expression has been previously detected in the mitral cells of the olfactory bulb, ganglion cells of the retina, and all three cortical epithelial cell layers (Okano and Darnell, 1997; Clayton et al., 1998). In the present study, we found high levels of E1c in all of these regions at E14.5 of mouse brain development, further indicating that this variant encodes a HuD 5'UTR and/or N-terminal peptide that has(ve) an important function(s).

The function of E1c may also be related to the expression of an uncharacterized noncoding RNA (ncRNA). A recent study using human fetal brain to search for intermediate sized ncRNAs uncovered a novel ncRNA that maps directly within HuD E1c. The function of this particular ncRNA is unknown; however, its high abundance in the fetal brain implies a developmental role (Yan et al., 2011).

Induction of $\mathrm{HuD}$ mRNA has been previously described in neuronal development in vitro and in vivo (Clayton et al., 1998; Hambardzumyan et al., 2009). However, whether this altered expression occurs through transcriptional and/or posttranscriptional mechanisms was until now unknown. Here, we confirm that $\mathrm{HuD}$ mRNA expression gradually increases in differentiating neuronal P19s to levels $(\sim 5 \times$ at day 4 of P19 neurogenesis) that match those previously detected (Mansfield and Keene, 2012).

In addition, we used several complementary approaches to demonstrate that $\mathrm{HuD}$ expression is transcriptionally regulated in developing P19 neurons. These results indicate that the induction in $\mathrm{HuD}$ mRNA levels during P19 neurogenesis can be solely ascribed to transcriptional mechanisms. Transcriptional events driving mRNA expression during neurogenesis has been previously described for several genes, including GAP-43 and AChE (Greene and Rukenstein, 1981; Zhao et al., 2012). However, contrary to our findings on $\mathrm{HuD}$ expression, increased mRNA stability has also been shown to play a role in the expression of both of these genes, although later in neuronal development (Mobarak et al., 2000; Deschenes-Furry et al., 2003) (for review see Bolognani and Perrone-Bizzozero, 2008; Bronicki and Jasmin, 2012). The absence of distinct post-transcriptional regulation observed in our studies between neuronal and mesodermal cells suggests that expression of certain RBPs and/or miRNAs during early P19 differentiation is similar.

Since we detected predominant expression of the E1c variant and transcriptional regulation of $\mathrm{HuD}$, we characterized the E1c promoter region and the cis- and trans-acting factor(s) governing 
$\mathrm{HuD}$ transcription. We determined the E1c TSS based on the longest clone obtained from our 5'RACE analysis; however, we cannot entirely rule out the possibility of other TSSs in this vicinity, as previously published (Inman et al., 1998). Our analysis of the E1c 5'RR indicates that no typical components of core promoters, such as TATA-box, Initiator element, or GC-rich region (Juven-Gershon and Kadonaga, 2010; Lenhard et al., 2012), are located within $-40 \mathrm{bp}$ of the TSS. Nonetheless, we found a putative CREB, C/EBP, Sp1, and MyT1 motif further upstream in the proximal promoter region, some of which are also present in mammalian $H u R$ (King et al., 2000), HuB (King, 1996), and/or zebrafish $\mathrm{HuC}$ (Park et al., 2000) promoters. Importantly, we demonstrated that the E1c proximal promoter region was sufficient to produce basal expression in both neuronal and mesodermal cells. Moreover, further upstream of E1c, we identified a well conserved $\sim 400$ bp region that enhanced gene expression specifically in neurons. This $400 \mathrm{bp}$ region shares a high degree of homology with an elrD promoter fragment that was shown to induce neuron-restrictive reporter expression during Xenopus development (Nassar and Wegnez, 2001).

A striking feature of the $400 \mathrm{bp}$ DNA region was the presence of several putative proneural cis-elements, namely E-boxes (5' CANNTG $3^{\prime}$ ). We demonstrate that the 400 bp region contains five E-boxes and is particularly responsive to Ngn2. Further analysis of these five E-boxes revealed that two of them (E-box 2 and 3 ) are necessary for Ngn2-dependent transcription.

Our findings are in agreement with converging lines of evidence indicating that Ngn2 contributes to $\mathrm{HuD}$ expression. First, Ngn2 is a neuron-restricted transcription factor that is important for promoting cell cycle exit and neuronal differentiation, similar to $\mathrm{HuD}$ (for review, see Guillemot, 2007). Second, during cortical development, the temporal expression of Ngn2 precedes that of $\mathrm{HuD}$ (Fode et al., 1998). Third, Ngn2 is expressed in several similar embryonic brain neuronal populations as $\mathrm{HuD} \mathrm{E} 1 \mathrm{c}$, including the ventricular zone of the cerebral cortex, hippocampus, and retina (Allen Developing Mouse Brain Atlas; http:// developingmouse.brain-map.org). Last, Ngn2 mutant mice have decreased HuD levels (Mattar et al., 2004). Collectively, these results emphasize the importance of $\mathrm{Ngn} 2$ to E1c-bearing $\mathrm{HuD}$ transcription.

In summary, we found that the mammalian $H u D$ gene contains eight leader exons with the possibility that most of them encode alternate $\mathrm{N}$ termini of the $\mathrm{HuD}$ protein. Our study is also the first to identify a positive regulatory event that induces $\mathrm{HuD}$ mRNA expression. Given that expression of $\mathrm{HuD}$ is altered during learning and memory (Quattrone et al., 2001), nerve regeneration (Anderson et al., 2003; Deschênes-Furry et al., 2007), and neurological disorders (Noureddine et al., 2005; Bolognani et al., 2007; Tiruchinapalli et al., 2008; Amadio et al., 2009; Hubers et al., 2011), it seems reasonable to postulate that under these conditions, the expression and/or function of E1 variants are specifically affected. Moreover, Ngn2 has also been linked to learning and memory (Galichet et al., 2008) and neurological disorders (Uhrig et al., 2009), thereby raising the interesting possibility that Ngn2-dependent HuD transcription is causally or casually involved in these physiological and pathological conditions. Based on our findings and the multifunctional nature of $\mathrm{HuD}$, it becomes evident that a thorough knowledge of the molecular machinery that promotes expression of this master regulator is important for understanding not only neuronal development and function, but also various neuronal disease states.

\section{References}

Abdelmohsen K, Hutchison ER, Lee EK, Kuwano Y, Kim MM, Masuda K, Srikantan S, Subaran SS, Marasa BS, Mattson MP, Gorospe M (2010) miR-375 inhibits differentiation of neurites by lowering HuD levels. Mol Cell Biol 30:4197-4210.

Abe R, Yamamoto K, Sakamoto H (1996) Target specificity of neuronal RNA-binding protein, mel-N1: Direct binding to the $3^{\prime}$ untranslated region of its own mRNA. Nucleic Acids Res 24:2011-2016.

Amadio M, Pascale A, Wang J, Ho L, Quattrone A, Gandy S, Haroutunian V, Racchi M, Pasinetti GM (2009) nELAV proteins alteration in alzheimer's disease brain: A novel putative target for amyloid-beta reverberating on AbetaPP processing. J Alzheimers Dis 16:409-419.

Anderson KD, Merhege MA, Morin M, Bolognani F, Perrone-Bizzozero NI (2003) Increased expression and localization of the RNA-binding protein $\mathrm{HuD}$ and GAP-43 mRNA to cytoplasmic granules in DRG neurons during nerve regeneration. Exp Neurol 183:100-108.

Bertrand N, Castro DS, Guillemot F (2002) Proneural genes and the specification of neural cell types. Nat Rev Neurosci 3:517-530.

Bolognani F, Perrone-Bizzozero NI (2008) RNA-protein interactions and control of mRNA stability in neurons. J Neurosci Res 86:481-489.

Bolognani F, Tanner DC, Nixon S, Okano HJ, Okano H, Perrone-Bizzozero NI (2007) Coordinated expression of HuD and GAP-43 in hippocampal dentate granule cells during developmental and adult plasticity. Neurochem Res 32:2142-2151.

Bolognani F, Contente-Cuomo T, Perrone-Bizzozero NI (2010) Novel recognition motifs and biological functions of the RNA-binding protein $\mathrm{HuD}$ revealed by genome-wide identification of its targets. Nucleic Acids Res 38:117-130.

Boudreau-Larivière C, Chan RY, Wu J, Jasmin BJ (2000) Molecular mechanisms underlying the activity-linked alterations in acetylcholinesterase mRNAs in developing versus adult rat skeletal muscles. J Neurochem 74:2250-2258.

Bronicki LM, Jasmin BJ (2012) Trans-acting factors governing acetylcholinesterase mRNA metabolism in neurons. Front Mol Neurosci 5:36.

Cartharius K, Frech K, Grote K, Klocke B, Haltmeier M, Klingenhoff A, Frisch M, Bayerlein M, Werner T (2005) MatInspector and beyond: Promoter analysis based on transcription factor binding sites. Bioinformatics 21:2933-2942.

Clayton GH, Perez GM, Smith RL, Owens GC (1998) Expression of mRNA for the elav-like neural-specific RNA binding protein, $\mathrm{HuD}$, during nervous system development. Brain Res Dev Brain Res 109:271-280.

Clow C, Jasmin BJ (2010) Brain-derived neurotrophic factor regulates satellite cell differentiation and skeltal muscle regeneration. Mol Biol Cell 21:2182-2190.

Cuadrado A, Navarro-Yubero C, Furneaux H, Muñoz A (2003) Neuronal $\mathrm{HuD}$ gene encoding a mRNA stability regulator is transcriptionally repressed by thyroid hormone. J Neurochem 86:763-773.

Deschenes-Furry J, Belanger G, Perrone-Bizzozero N, Jasmin BJ (2003) Post-transcriptional regulation of acetylcholinesterase mRNAs in nerve growth factor-treated PC12 cells by the RNA-binding protein HuD. J Biol Chem 278:5710-5717.

Deschênes-Furry J, Perrone-Bizzozero N, Jasmin BJ (2006) The RNAbinding protein $\mathrm{HuD}$ : A regulator of neuronal differentiation, maintenance and plasticity. Bioessays 28:822-833.

Deschênes-Furry J, Mousavi K, Bolognani F, Neve RL, Parks RJ, PerroneBizzozero NI, Jasmin BJ (2007) The RNA-binding protein HuD binds acetylcholinesterase mRNA in neurons and regulates its expression after axotomy. J Neurosci 27:665-675.

Fode C, Gradwohl G, Morin X, Dierich A, LeMeur M, Goridis C, Guillemot F (1998) The bHLH protein NEUROGENIN 2 is a determination factor for epibranchial placode-derived sensory neurons. Neuron 20:483-494.

Galichet C, Guillemot F, Parras CM (2008) Neurogenin 2 has an essential role in development of the dentate gyrus. Development 135:2031-2041.

Gramolini AO, Jasmin BJ (1999) Expression of the utrophin gene during myogenic differentiation. Nucleic Acids Res 27:3603-3609.

Greene LA, Rukenstein A (1981) Regulation of acetylcholinesterase activity by nerve growth factor. role of transcription and dissociation from effects on proliferation and neurite outgrowth. J Biol Chem 256:6363-6367.

Guillemot F (2007) Spatial and temporal specification of neural fates by transcription factor codes. Development 134:3771-3780.

Hambardzumyan D, Sergent-Tanguy S, Thinard R, Bonnamain V, Masip M, Fabre A, Boudin H, Neveu I, Naveilhan P (2009) AUF1 and hu proteins 
in the developing rat brain: Implication in the proliferation and differentiation of neural progenitors. J Neurosci Res 87:1296-1309.

Hellman LM, Fried MG (2007) Electrophoretic mobility shift assay (EMSA) for detecting protein-nucleic acid interactions. Nat Protoc 2:1849-1861.

Hinman MN, Lou H (2008) Diverse molecular functions of hu proteins. Cell Mol Life Sci 65:3168-3181.

Hubers L, Valderrama-Carvajal H, Laframboise J, Timbers J, Sanchez G, C ôté J (2011) HuD interacts with survival motor neuron protein and can rescue spinal muscular atrophy-like neuronal defects. Hum Mol Genet 20:553-579.

Inman MV, Levy S, Mock BA, Owens GC (1998) Gene organization and chromosome location of the neural-specific RNA binding protein Elavl4. Gene 208:139-145.

Jacox E, Gotea V, Ovcharenko I, Elnitski L (2010) Tissue-specific and ubiquitous expression patterns from alternative promoters of human genes. PLoS One 5:e12274.

Juven-Gershon T, Kadonaga JT (2010) Regulation of gene expression via the core promoter and the basal transcriptional machinery. Dev Biol 339:225-229.

Kim S, Yoon YS, Kim JW, Jung M, Kim SU, Lee YD, Suh-Kim H (2004) Neurogenin 1 is sufficient to induce neuronal differentiation of embryonal carcinoma P19 cells in the absence of retinoic acid. Cell Mol Neurobiol 24:343-356.

King PH (1996) Cloning the 5' flanking region of neuron-specific hel-N1: Evidence for positive regulatory elements governing cell-specific transcription. Brain Res 723:141-147.

King PH, Fuller JJ, Nabors LB, Detloff PJ (2000) Analysis of the 5' end of the mouse Elavl1 (mHuA) gene reveals a transcriptional regulatory element and evidence for conserved genomic organization. Gene 242:125-131.

Lee EK, Kim W, Tominaga K, Martindale JL, Yang X, Subaran SS, Carlson OD, Mercken EM, Kulkarni RN, Akamatsu W, Okano H, PerroneBizzozero NI, de Cabo R, Egan JM, Gorospe M (2012) RNA-binding protein $\mathrm{HuD}$ controls insulin translation. Mol Cell 45:826-835.

Lenhard B, Sandelin A, Carninci P (2012) Metazoan promoters: emerging characteristics and insights into transcriptional regulation. Nat Rev Genet 13:233-245.

Mansfield KD, Keene JD (2012) Neuron-specific ELAV/Hu proteins suppress $\mathrm{HuR}$ mRNA during neuronal differentiation by alternative polyadenylation. Nucleic Acids Res 40:2734-2746.

Mattar P, Britz O, Johannes C, Nieto M, Ma L, Rebeyka A, Klenin N, Polleux F, Guillemot F, Schuurmans C (2004) A screen for downstream effectors of Neurogenin2 in the embryonic neocortex. Dev Biol 273:373-389.

McBurney MW, Jones-Villeneuve EM, Edwards MK, Anderson PJ (1982) Control of muscle and neuronal differentiation in a cultured embryonal carcinoma cell line. Nature 299:165-167.

Meshorer E, Toiber D, Zurel D, Sahly I, Dori A, Cagnano E, Schreiber L, Grisaru D, Tronche F, Soreq H (2004) Combinatorial complexity of 5' alternative acetylcholinesterase transcripts and protein products. J Biol Chem 279:29740-29751.

Mobarak CD, Anderson KD, Morin M, Beckel-Mitchener A, Rogers SL, Furneaux H, King P, Perrone-Bizzozero NI (2000) The RNA-binding protein $\mathrm{HuD}$ is required for GAP-43 mRNA stability, GAP-43 gene expression, and PKC-dependent neurite outgrowth in PC12 cells. Mol Biol Cell 11:3191-3203.

Nassar F, Wegnez M (2001) Characterization of two promoters of the xenopus laevis elrD gene. Biochem Biophys Res Commun 283:392-398.

Noureddine MA, Qin XJ, Oliveira SA, Skelly TJ, van der Walt J, Hauser MA, Pericak-Vance MA, Vance JM, Li YJ (2005) Association between the neuron-specific RNA-binding protein ELAVL4 and parkinson disease. Hum Genet 117:27-33.
Okano HJ, Darnell RB (1997) A hierarchy of hu RNA binding proteins in developing and adult neurons. J Neurosci 17:3024-3037.

Ovcharenko I, Nobrega MA, Loots GG, Stubbs L (2004) ECR browser: A tool for visualizing and accessing data from comparisons of multiple vertebrate genomes. Nucleic Acids Res 32:W280-W286.

Park HC, Kim CH, Bae YK, Yeo SY, Kim SH, Hong SK, Shin J, Yoo KW, Hibi M, Hirano T, Miki N, Chitnis AB, Huh TL (2000) Analysis of upstream elements in the $\mathrm{HuC}$ promoter leads to the establishment of transgenic zebrafish with fluorescent neurons. Dev Biol 227:279-293.

Pascale A, Govoni S (2012) The complex world of post-transcriptional mechanisms: Is their deregulation a common link for diseases? focus on ELAV-like RNA-binding proteins. Cell Mol Life Sci 69:501-517.

Pascale A, Amadio M, Quattrone A (2008) Defining a neuron: neuronal ELAV proteins. Cell Mol Life Sci 65:128-140.

Quattrone A, Pascale A, Nogues X, Zhao W, Gusev P, Pacini A, Alkon DL (2001) Posttranscriptional regulation of gene expression in learning by the neuronal ELAV-like mRNA-stabilizing proteins. Proc Natl Acad Sci U S A 98:11668-11673.

Ravel-Chapuis A, Vandromme M, Thomas JL, Schaeffer L (2007) Postsynaptic chromatin is under neural control at the neuromuscular junction. EMBO J 26:1117-1128.

Rolfe FG, Sewell WA (1997) Analysis of human interleukin-5 gene transcription by a novel nuclear run on method based on the polymerase chain reaction. J Immunol Methods 202:143-151.

Samson ML (1998) Evidence for 3' untranslated region-dependent autoregulation of the drosophila gene encoding the neuronal nuclear RNAbinding protein ELAV. Genetics 150:723-733.

Seo S, Lim JW, Yellajoshyula D, Chang LW, Kroll KL (2007) Neurogenin and NeuroD direct transcriptional targets and their regulatory enhancers. EMBO J 26:5093-5108.

Sharova LV, Sharov AA, Nedorezov T, Piao Y, Shaik N, Ko MS (2009) Database for mRNA half-life of 19977 genes obtained by DNA microarray analysis of pluripotent and differentiating mouse embryonic stem cells. DNA Res 16:45-58.

Shen CP, Kadesch T (1995) B-cell-specific DNA binding by an E47 homodimer. Mol Cell Biol 15:4518-4524.

Showell C, Binder O, Conlon FL (2004) T-box genes in early embryogenesis. Dev Dyn 229:201-218.

Tiruchinapalli DM, Caron MG, Keene JD (2008) Activity-dependent expression of ELAV/Hu RBPs and neuronal mRNAs in seizure and cocaine brain. J Neurochem 107:1529-1543.

Turner JD, Alt SR, Cao L, Vernocchi S, Trifonova S, Battello N, Muller CP (2010) Transcriptional control of the glucocorticoid receptor: $\mathrm{CpG}$ islands, epigenetics and more. Biochem Pharmacol 80:1860-1868.

Uhrig M, Ittrich C, Wiedmann V, Knyazev Y, Weninger A, Riemenschneider M, Hartmann T (2009) New alzheimer amyloid beta responsive genes identified in human neuroblastoma cells by hierarchical clustering. PLoS One 4:e6779.

Yan D, He D, He S, Chen X, Fan Z, Chen R (2011) Identification and analysis of intermediate size noncoding RNAs in the human fetal brain. PLoS One 6:e21652.

Yannoni YM, White K (1999) Domain necessary for drosophila ELAV nuclear localization: function requires nuclear ELAV. J Cell Sci $112[\mathrm{Pt}$ 24]:4501-4512.

Young WJ, Chang C (1998) Ontogeny and autoregulation of androgen receptor mRNA expression in the nervous system. Endocrine 9:79-88.

Zhao JC, Zhang LX, Zhang Y, Shen YF (2012) The differential regulation of Gap43 gene in the neuronal differentiation of P19 cells. J Cell Physiol 227:2645-2653 